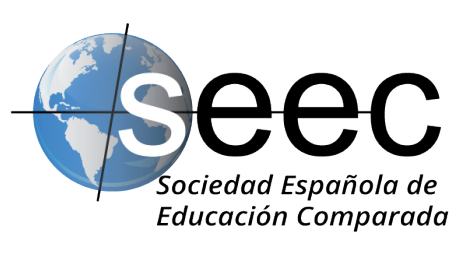

\title{
Tendencias privatizadoras del modelo de financiación de la educación superior en Europa. Propuestas de la Unión Europea y análisis del acceso asequible
}

Privatizing trends in the financing model of higher education in Europe. Proposals of the European Union and analysis of affordable access

\section{Alexandra Carrasco González*}

DoI: $10.5944 /$ reec.37.2021.28047

Recibido: 17 de agosto de 2020 Aceptado: 23 de octubre de 2020

\footnotetext{
*Alexandra Carrasco GonzÁlez: Personal docente e investigador adscrita al Departamento de Educación Comparada e Historia de la Educación (ECHE) de la Universidad de Valencia. Miembro del grupo de investigación POLISOC (Políticas Educativas, Interculturalidad y Sociedad). Datos de contacto: e-mail: alexandra.carrasco@uv.es
} 


\title{
Resumen
}

La influencia que ejercen organismos supranacionales como la Unión Europea (UE) en la configuración de políticas educativas nos obliga a incluir la esfera supranacional en el estudio de las tendencias educativas. Una tendencia en auge en el ámbito de la educación superior es el aumento de la inversión privada y nuestro objetivo es medir su impacto en los últimos años en el contexto europeo, y si pone en riesgo el acceso asequible de este nivel educativo. Para ello, en primer lugar, analizamos las diferentes acciones desarrolladas desde la Unión Europea sobre el incremento de financiación privada de la educación superior a través de diversos documentos y planes de trabajo. En segundo lugar, desde la metodología de Educación Comparada, contrastamos la variación de las fuentes de financiación de la educación superior en 20 países europeos, en una trayectoria de trece años (2002-2016), y su repercusión en el acceso asequible de la educación superior, principalmente a través del análisis de las tasas económicas y los sistemas de ayudas a estudiantes. Los resultados, por un lado, nos indican que la UE justifica el aumento de la financiación privada de las universidades como estrategia global para lograr una mayor competitividad dentro del contexto de la sociedad del conocimiento. Por otro lado, existe una tendencia hacia la privatización de los modelos de financiación de la educación superior en los países europeos, llegando incluso a poner en riesgo el acceso asequible de la educación superior en países como España, Grecia, Irlanda, Italia y Portugal.

Palabras clave: educación superior; educación comparada; acceso asequible; Unión Europea.

\begin{abstract}
The influence exerted by supranational organizations, such as the European Union (EU) in the configuration of educational policies, forces us to include the supranational sphere in the study of educational trends. A growing trend in the field of higher education is the increase in private investment and our objective is to measure its impact in recent years in the European context and if it puts at risk the affordable access to this educational level. To do this, in the first place, we analyze the different actions developed from the European Union on increasing private financing of higher education through various documents and work plans. Second, from the Comparative Education methodology, we compare the variation in the sources of financing for higher education in 20 European countries, over a 13-year trajectory (2002-2016), and its impact on affordable access to education higher, through the analysis of economic rates and student aid systems. The results, on the one hand, indicate that the EU justifies the increase in private financing of universities, as a global strategy to achieve greater competitiveness within the context of the knowledge society. On the other hand, there is a trend towards the privatization of financing models for higher education in European countries, which countries such as Spain, Greece, Ireland, Italy and Portugal, put at risk the affordable access to higher education.
\end{abstract}

Keywords: higher education; comparative education; affordable access; European Union. 


\section{Introducción}

La influencia de los organismos supranacionales en el diseño de políticas educativas viene acompañada de los dos fenómenos más importantes y poderosos del siglo XXI: la privatización y la globalización, que han terminado extendiéndose por todo el mundo y ambos están estrechamente relacionados (Tilak, 2006). El mayor impacto de la globalización sobre los Estados ha sido definido como la pérdida de capacidad estatal para crear políticas nacionales independientes (Dale, 2007), produciéndose una cesión de responsabilidades a los organismos supranacionales (Tarabini y Bonal, 2011). Desde esta lógica, estas organizaciones se convierten en nuevos agentes que intervienen en el diseño de las políticas educativas. El interés de los organismos internacionales en política educativa ha ido creciendo notablemente en los últimos años, y su cada vez mayor implicación en acciones educativas va marcando sutilmente una determinada forma de entender algunas cuestiones en política educativa (Valle, 2012).

Esta investigación adopta un enfoque multinivel (Tarabini-Castellani y Bonal, 2011), integrando la esfera supranacional en el estudio de la tendencias privatizadoras de los modelos de financiación de la educación superior (ES) en 20 países europeos, puesto que parte de la idea de que muchas de las transformaciones de la ES han venido suscitadas por la influencia o el apoyo que ejercen los diferentes organismos supranacionales (Rizvi, 2016; Luzón y Torres, 2013). Si bien su proceso de privatización es complejo y engloba múltiples variables y factores, muchos de ellos contextuales e históricos, desde este estudio, se aporta una postura concreta centrada en incluir la influencia que puede ejercer la Unión Europea como organismo supranacional en el impulso de las tendencias de privatización de la educación superior europea.

Esta perspectiva se sustenta en la Política Educativa Supranacional (Valle, 2012), que tiene como objeto de estudio las políticas educativas de los organismos internacionales, entendiendo como política educativa «cualquier acción en materia educativa, o de enseñanza o formación, que se ponga en marcha desde estos organismos, o bien cualquier propuesta que surja desde ellos como recomendación de carácter global para la educación, la enseñanza o la formación» (Valle, 2012, p. 117).

La Unión Europea (UE) no tiene competencia para modificar las políticas educativas nacionales o para aprobar leyes educativas, pero mediante la aprobación de planes de trabajo, objetivos y recomendaciones, ejerce una ley blanda que, aunque no sea vinculante y los países no estén obligados a cumplirlos (Matarranz y Pérez, 2016), de un modo $\mathrm{u}$ otro va marcando una dirección concreta sobre algunas cuestiones relevantes en el campo de la ES, y en especial sobre la modernización de las universidades europeas.

Este trabajo, en primer lugar, se centra en recoger las recomendaciones, objetivos y planes de acción que marcan las directrices de reforma en política universitaria a los Estados miembros, impulsados desde la UE a partir de la Declaración de Lisboa (2000), con la intención principal de analizar las medidas que enfatizan la participación del sector privado en la financiación de la ES y su consideración como un bien de inversión individual.

En segundo lugar, se muestra una comparativa de las trayectorias de los modelos de financiación de la ES que han adoptado 20 países europeos desde 2002 a 2016, con el doble objetivo de, por un lado, estudiar qué países europeos han privatizado su modelo de financiación, especialmente mediante modelos de repartición de costes, y, por otro, evaluar cómo afecta ese modelo de repartición a un acceso asequible, desde el punto de vista económico. 
Entendemos que la educación superior como un bien público es aquella donde las tres áreas de política universitaria -la titularidad, provisión y financiación- quedan casi completamente cubiertas por el sector público, mientras que el proceso de privatización supone una mayor participación del sector privado en alguna de estas áreas (Verger, 2013).

Este estudio se focaliza en la privatización de la ES desde el análisis de las fuentes de financiación, pero integra las otras dos áreas (titularidad y provisión) a lo largo de la investigación y, en especial, atiende a la tendencia bastante extendida de distribución de costes, donde principalmente su coste ha pasado de ser casi exclusivamente responsabilidad de los Gobiernos a ser compartida con los alumnos y sus familias, a través del aumento de la tasa de matrícula o con la introducción de sistemas de ayudas a estudiantes basados en prestamos.

La problemática de partida es que la privatización de la ES centrada en la repartición de costes, por un lado, modifica la manera de entender la ES, dejando de considerarse como un bien público para convertirse en un bien de inversión individual, un cambio de concepción que trae cambios sociales que en la práctica pueden generar desigualdades. Por otro lado, el establecimiento de tasas de matrícula a estudiantes, si no se acompaña de buenos sistemas de ayudas económicas (becas y/o prestamos), pone en riesgo el acceso asequible desde un punto de vista económico. Un acceso asequible a la ES desde un análisis económico es aquel que permite el acceso a los estudiantes sin que el importe de tasas económicas suponga una barrera, a través de una adecuada combinación entre los precios de matrícula o gratuidad, con los sistemas de ayudas públicas que reciben (becas y/o prestamos). El acceso asequible económico es un concepto consagrado en la meta 4.3 de los ODS (Objetivos de Desarrollo Sostenible) y, en los últimos años, está cobrando una mayor importancia dada la tendencia mundial hacia el reparto de costes en ES (Unesco, 2017).

En definitiva, este trabajo analiza: las acciones de la UE dirigidas a promocionar el incremento de inversión privada en ES y la influencia de este organismo en las políticas de ES nacionales; arroja luz sobre las tendencias privatizadoras y, en algunos casos, desprivatizadoras de los modelos de financiación de 20 países europeos; y, en concreto, aporta la relación entre procesos de privatización y la garantía de un acceso asequible en Europa. Si bien entendemos que el impulso de recomendaciones y planes de acción proprivatización de la UE en ES no es la única variable que puede interferir en su proceso de privatización, es necesario tener en cuenta la influencia que pueden ejercer en este sentido los organismos internacionales. Al mismo tiempo, a lo largo del estudio se incluyen otras variables contextuales que nos ayudan a comprender con mayor profundidad las tendencias de privatización en Europa.

\section{Marco metodológico}

Primero, con el propósito de valorar las acciones y recomendaciones desarrolladas desde la UE que enfatizan la privatización de la financiación de la educación superior, esta investigación recoge: por un lado, los objetivos marcados y planes estratégicos, aprobados por el Consejo Europeo; y por otro lado, los intereses de la UE en cuanto a las reformas de la ES y las universidades, a través de los documentos publicados por la Comisión Europea. Todo ello, a partir de la Declaración de Lisboa en el año 2000, porque es cuando se ponen en marcha todas estas reformas. Asimismo, se analiza las diferentes formas desde las que la UE influye mediante estos mecanismos en las políticas educativas nacionales europeas. 
La educación no es un ámbito en el que la UE tenga competencia para elaborar legislación. Por ello, nos centramos en dos de los órganos europeos que mayor influencia ejercen en política educativa. El Consejo Europeo, compuesto por los jefes de Estado de los Estados miembros, su presidente y el presidente de la Comisión, que orienta las prioridades y marca objetivos en políticas educativas. La Comisión Europea, que representa los intereses de la UE, por lo que a través de diferentes documentos comunica los intereses en política educativa de la UE a los países miembros y da recomendaciones sobre las líneas a seguir en política educativa.

Segundo, atendiendo al objetivo centrado en estudiar las tendencias generales de los modelos de financiación de la ES de los países europeos y, en concreto, en detectar aquellos países que han acentuado su privatización desarrollando modelos de repartición de costes en ES, el estudio utiliza el método comparativo propio de la Educación Comparada para contrastar las variables de gasto total, gasto público, gasto privado (dividido en gasto familiar y gasto de otras entidades privadas) y gasto internacional en instituciones de educación terciara de 20 países europeos de 2002 a 2016. Dicho periodo se debe a que es el más largo y actual, de acuerdo con las variables analizadas, del que se disponen datos, apoyándonos en los informes anuales de la OCDE «Education at Glance».

La población está conformada por el total de los 27 países que forman parte de la UE en la actualidad, año 2020. En el estudio hemos incluido a Reino Unido, porque durante la perspectiva de tiempo abordada (2002-2016) pertenecía a la Unión Europea, aunque desde 2020 ya no es un país miembro. Del total de países (28), se han seleccionado 20 para la investigación: Alemania, Austria, Bélgica, Dinamarca, Eslovaquia, Eslovenia, España, Estonia, Finlandia, Francia, Grecia, Hungría, Irlanda, Italia, Países Bajos, Polonia, Portugal, Reino Unido, República Checa y Suecia. Por falta de datos en los informes de la OCDE se han excluido: Bulgaria, Chipre, Croacia, Malta, Rumania, Lituania, Letonia y Luxemburgo.

Tercero, con el objetivo de analizar cómo puede afectar la privatización del modelo de financiación basado en la repartición de costes al acceso asequible de la ES, se recogen y contrastan datos de diferentes informes de la OCDE, la Comisión Europea y la base de datos de este último organismo, Eurostat, que proporciona información para el análisis del acceso asequible, atendiendo: al importe de tasas económicas tanto en IES (Instituciones de Educación Superior) públicas como privadas; el porcentaje de estudiantes beneficiarios de sistemas de ayudas públicos (becas y/o prestamos); el porcentaje de inversión pública destinado al sistema de ayudas económicas a estudiantes; y el de alumnos matriculados en IES públicas y privadas, todo ello tanto para 2002 como para 2016.

Los datos se enfocan en las Instituciones de Educación Terciaria que teniendo en cuenta la Clasificación Internacional Normalizada de la Educación (CINE, 2011), hace referencia a nivel CINE 5 (educación terciaria de ciclo corto), CINE 6 (nivel de grado o equivalente), CINE 7 (nivel de máster o equivalente) y CINE 8 (nivel de doctorado o equivalente), y para instituciones públicas y privadas de enseñanza universitaria o no universitaria.

El trabajo se focaliza en las instituciones universitarias, que engloban CINE 6, 7 y 8 (grado, máster y doctorado), aunque indistintamente se utilicen los conceptos de ES o IES, que también incluyen CINE 5. Esto se debe a que, por un lado, el análisis de la UE se centra en universidades y, por otro lado, los países de la muestra presentan el grosor de su porcentaje de matriculados en CINE 6 (grado), según el indicador «Del total de estudiantes en educación terciaria, por nivel de educación terciaria para 2016» 
(edu_uoe_enrto8), datos de Eurostat para 2016. Solo países como Austria, Eslovenia, España, Francia y Dinamarca muestran porcentajes (entorno al 10 \%) en CINE 5, pero no es un nivel representativo ni objeto de estudio de esta investigación.

\section{La Unión Europea y el incremento de la inversión total en educación superior como objetivo estratégico}

Conocimiento y formación han sido dos aspectos clave desde que el Consejo Europeo celebrado en Lisboa se propusiera como objetivo estratégico para la década de 2010 convertir a la UE en la economía basada en el conocimiento más competitiva y dinámica del mundo capaz de crecer económicamente de manera sostenible con más y mejores empleos, y con mayor cohesión social (Consejo Europeo de Lisboa, 2000). Para ello, desarrolló una estrategia global de política económica y social, denominada Estrategia Lisboa, que servía de marco para que los Gobiernos europeos pudieran dar respuesta conjuntamente a los diferentes retos a los que se enfrentaban.

En la Estrategia Lisboa, el Consejo especificó que se requería modernizar el modelo social europeo a través de una mayor inversión en capital humano e instaba a los Estados miembros a que consiguieran un aumento anual considerable de la inversión per cápita en recursos humanos (Consejo Europeo de Lisboa, 2000).

Dos años más tarde, el Consejo Europeo de Barcelona, para poder acortar las distancias con sus principales competidores mencionando a EE. UU. y Japón, fijó un doble objetivo para la investigación: aumentar el gasto global en I+D e innovación en la UE hasta alcanzar el $3 \%$ del PIB para 2010; y lograr que dos tercios de estos nuevos fondos proviniesen del sector privado. Además, estableció como nueva meta convertir a los sistemas de ES en una referencia de calidad mundial para 2010 (Consejo Europeo de Barcelona, 2002).

En 2006, el Consejo Europeo celebrado el 23 y 24 de marzo en Bruselas, tras cinco años de aplicación de la Estrategia Lisboa, se reunió para realizar un relanzamiento de la Estrategia y abordar ámbitos específicos de actuación prioritaria antes de 2007, entre los que señaló la educación y la formación, ya que eran factores clave para la competitividad de la UE y la cohesión social. Así, estableció como actuación prioritaria una mayor inversión en conocimiento e innovación, e instó a los Estados miembros a facilitar el acceso de las universidades a fuentes de financiación complementarias, incluidas las privadas, y eliminar los obstáculos de las universidades a asociarse con las empresas (Consejo Europeo de Bruselas, 2006).

Estas propuestas fijaban modificaciones en políticas de I+D y de educación superior, convirtiéndolas en principales elementos de competitividad en la sociedad de conocimiento. De este modo, los niveles de inversión y la calidad de los sistemas de estudios superiores se convirtieron en cuestiones centrales de la UE, dando lugar al desarrollo de dos planes de acción en el ámbito de educación. Asimismo, desde la Comisión Europea se elaboraron tres agendas europeas dirigidas a la reforma de las universidades y la ES, y se publicaron comunicaciones que se centraban en marcar las directrices que orientaban las reformas en política de enseñanza superior de los Estados miembros.

Los dos planes de acción en el ámbito educativo desarrollados por la Estrategia Lisboa para alcanzar los objetivos propuestos fueron, primero, «Educación y Formación 2010» 
(ET 2010, por sus siglas en inglés Education and Training), que comprendía de 2000 hasta 2010 y planteaba un total de tres objetivos estratégicos; y, más tarde, aprobado en base a los logros del ET 2010 y en relación a la Estrategia Europa (2020), el plan de acción «Educación y Formación 2020» (ET 2020), que abarcaba de 2010 a 2020 y abordaba cuatro objetivos estratégicos. Ambos marcos de acción compartían: «mejorar la calidad y la eficiencia de los sistemas de educación y formación», desde donde se marcaban directrices encaminadas al incremento de inversión en ES. El resto de objetivos variaba, pero en ambos marcos estratégicos se incluían pautas orientadas a que los Estados miembros facilitaran el acceso de los estudiantes a todos los niveles educativos, incluido el superior, y propusieran medidas que promovieran la equidad y cohesión social.

Para reforzar la consecución de los objetivos estratégicos planteados en el ET 2010, la Comisión en 2006 publicó la primera agenda educativa «Cumplir la agenda de modernización para las universidades: educación, investigación e innovación» (COM [2006] 208), en la que marcaba nueve directrices para la reforma política de las universidades europeas, una de ellas centrada en aumentar la financiación, así como mejorar la eficacia de la financiación en educación e investigación (COM [2006] 208). En este sentido, en la misma agenda educativa la Comisión propuso como objetivo hasta 2010 que «la UE dedique al menos el $2 \%$ de PIB (financiación pública y privada) a la modernización del sector de la educación superior» (COM [2006] 208, p. 8).

En diciembre de 2008, a través de la Comunicación «Un marco estratégico actualizado para la cooperación europea en el ámbito de la educación y la formación» (COM [2008] 865), la Comisión planteó que la modernización de las universidades fuera uno de los temas prioritarios del nuevo marco para la cooperación política en educación y formación de la Estrategia Lisboa, e indicó los cuatros objetivos estratégicos para la próxima década, que se recogieron en 2009 en el nuevo marco estratégico ET 2020 (2009/C 119/02).

La Comisión para reforzar la consecución de los objetivos estratégicos del ET 2020 promovió en 2011 una nueva agenda de modernización de la enseñanza superior (COM [2011] 567). En la nueva agenda resaltaba que muy pocas instituciones europeas gozan de reconocimiento mundial y volvía a insistir en la necesidad de seguir invirtiendo en ES para posicionarse en la carrera global del conocimiento, puesto que su inversión total en Europa seguía siendo demasiado baja en comparación con EE. UU. y Japón, y la principal diferencia era la escasa financiación privada en ES de la UE respecto a sus competidores. La Comisión establecía que la inversión pública debía seguir siendo la base de una ES sostenible, pero para alcanzar sistemas de alta calidad, se requería al mismo tiempo, fuentes adicionales de financiación privada (COM [2011] 567).

En 2017, la Comisión publicó: «Una agenda renovada de la UE para la educación superior» (COM [2017] 247) y, respecto a la inversión en la ES, esta agenda señalaba que era necesario fomentar una inversión eficaz y marcaba que se estaba empezando a utilizar el Fondo Europeo para Inversiones Estratégicas (FEIE) a fin de atraer inversiones privadas a actividades de ES específicas que ofrecen buenas perspectivas de rentabilidad financiera (COM [2017] 247).

La primera comunicación que se debe destacar en el ámbito de la educación publicada por la Comisión tras la Declaración Lisboa (2000) fue en 2002, bajo el título «Invertir eficazmente en educación y formación: un imperativo para Europa» (COM [2002] 779). En este documento, la Comisión presentó un nuevo paradigma de inversión en educación y formación para la UE, centrado en combinar inversiones públicas con una orientación 
específica e incrementar el gasto privado (empresas y particulares) como complemento de la inversión pública (COM [2002] 779). Este informe planteaba que uno de los principales desafíos de la UE era que padecía un déficit de financiación en recursos humanos en ámbitos esenciales para la economía del conocimiento como la ES, y exponía que el bajo nivel de financiación privada en ES de la UE constituía una de las principales diferencias con sus principales competidores, EE. UU. y Japón (COM [2002] 779).

En el resto de comunicaciones, la Comisión vuelve hacer alusión al déficit de inversión de la UE en ES y su principal directriz se ha centrado en la necesidad de incrementar la inversión privada para alcanzar mayor competitividad, mostrando como una buena fuente de ingresos privados la contribución que los estudiantes pueden realizar en forma de gastos de matrícula (COM [2002] 779; COM [2003] 58; COM [2005] 152; COM [2006] 208; COM [2006] 481; COM [2011] 567; COM [2017] 247).

Este organismo justifica la participación de los estudiantes resaltando que eran los principales beneficiarios porque les aseguraba ingresos más altos y un estatus social más elevado (COM [2005] 152). La Comisión apuntaba que los estudiantes de la ES obtenían importantes ingresos privados que no estaban suficientemente compensados por una fiscalidad progresiva (COM [2006] 481). Además, matizaba que «los derechos de matrícula en el mercado pueden mejorar la calidad de la enseñanza y de la gestión de las universidades, y reforzar la motivación de los estudiantes» (COM [2006] 481, p. 8). Por ello, este organismo, mediante estas recomendaciones, contribuye a la consideración de la ES como un bien de inversión individual. Si bien es conveniente señalar que la Comisión también ha marcado líneas para que los Gobiernos desarrollen medidas que garanticen el acceso en los diferentes niveles de educación, incluidos el superior.

Todas estas propuestas ejercen una influencia por parte de la UE sobre el diseño de las políticas educativas nacionales y enfatizan la privatización de la ES, ya que promueven el incremento de la inversión privada, con el objetivo de ganar una mayor competitividad en el ámbito internacional.

Los dos marcos de acción impulsados (ET 2010, ET 2020) se aplicaban mediante un mecanismo que introdujo la Estrategia Lisboa: el Método Abierto de Coordinación (MAC), que servía como guía y coordinación entre el Consejo Europeo y los Estados miembros para garantizar la dirección estratégica y el cumplimiento de los mandatos. El MAC ha sido calificado como una forma de ley blanda o «soft law» (María Chiodi, 2015), es decir, un sistema de gobernanza débil mediante el cual la UE influye en el diseño de las políticas educativas nacionales, dado que a través del establecimiento de objetivos comunes se instaura una interdependencia (Valle, 2015), en el sentido de que la consecución de los mismos depende de la participación conjunta entre los Estados miembros. En este caso, convertirse en la economía del conocimiento más competitiva del mundo por parte de la UE depende de un incremento de inversión en ES de los Estados miembros, por ser uno de los ámbitos esenciales en la sociedad del conocimiento.

La Comisión, a través de la publicación de los informes y agendas educativas, ejerce una influencia en las políticas nacionales de ES que puede entenderse desde la categoría de «Liderazgo reflexivo» (Valle, 2015). Esto nos ayuda comprender como mediante la elaboración de documentos, que actúan como marcos reflexivos universales, las organizaciones van marcando las tendencias que deben seguir las políticas educativas, alienándolas hacia reformas comunes.

En general, los principales objetivos de la UE se centran en garantizar la cohesión social y en incrementar su competitividad internacional. En el ámbito de ES, estos objetivos 
pueden traducirse en demandas contrapuestas: por un lado, políticas que garantizan el acceso equitativo y asequible de la ES; y, por otro, aquellas que enfatizan la privatización de la ES, fomentando una mayor participación del sector privado en su financiación. Una adecuada combinación de estas políticas en los diferentes contextos será fundamental para no poner en riesgo el acceso asequible de la ES y no fomentar su privatización.

\section{Tendencias del modelo de financiación de la ES en los países europeos y el análisis del acceso asequible}

Antes de exponer las tendencias de privatización de la ES en los 20 países europeos, en base al estudio de las fuentes de financiación, es pertinente comentar algunos datos relativos a otros dos elementos que engloban el proceso de privatización: la matrícula y la cobertura. Por ello, se presenta: el porcentaje de alumnos matriculados en educación terciaria y su evolución durante (2002-2016), atendiendo al indicador de tasa bruta de matriculación en educación terciaria (CINE 5-8), expresado en porcentaje para ambos sexos, y como un porcentaje de la población total del grupo de edad de cinco años después de finalizar la escuela secundaria, de la base de datos DataBank; así como datos relativos al porcentaje de alumnos matriculados en IES públicas o privadas para los países de la muestra, según datos analizados en los informes «Education at Glance» de OCDE (2006, 2007 y 2019) sobre el porcentaje de estudiantes (en grado, máster y doctorado) matriculados en IES públicas, privadas dependientes o privadas independientes para estudiantes nacionales e internacionales para los cursos 2003/04 y 2017/18 o próximos.

En primer lugar, atendiendo el indicador de cobertura para 2016, destacamos que la mitad de países (10/20) dan una cobertura superior al 70 \% en educación terciaria, el resto (7/20) entorno al $60 \%$, y tan solo países (2/20) muestran valores próximos a $40 \%$. Además, todos los países presentan para 2016, el grosor de su porcentaje en el nivel de CINE 6 (grado), y en conjunto, en la enseñanza universitaria (CINE 6-8) (datos Eurostat), y la mayoría (16/20) han aumentado sus tasas de acceso a la educación terciaria de 2002 a 2016.

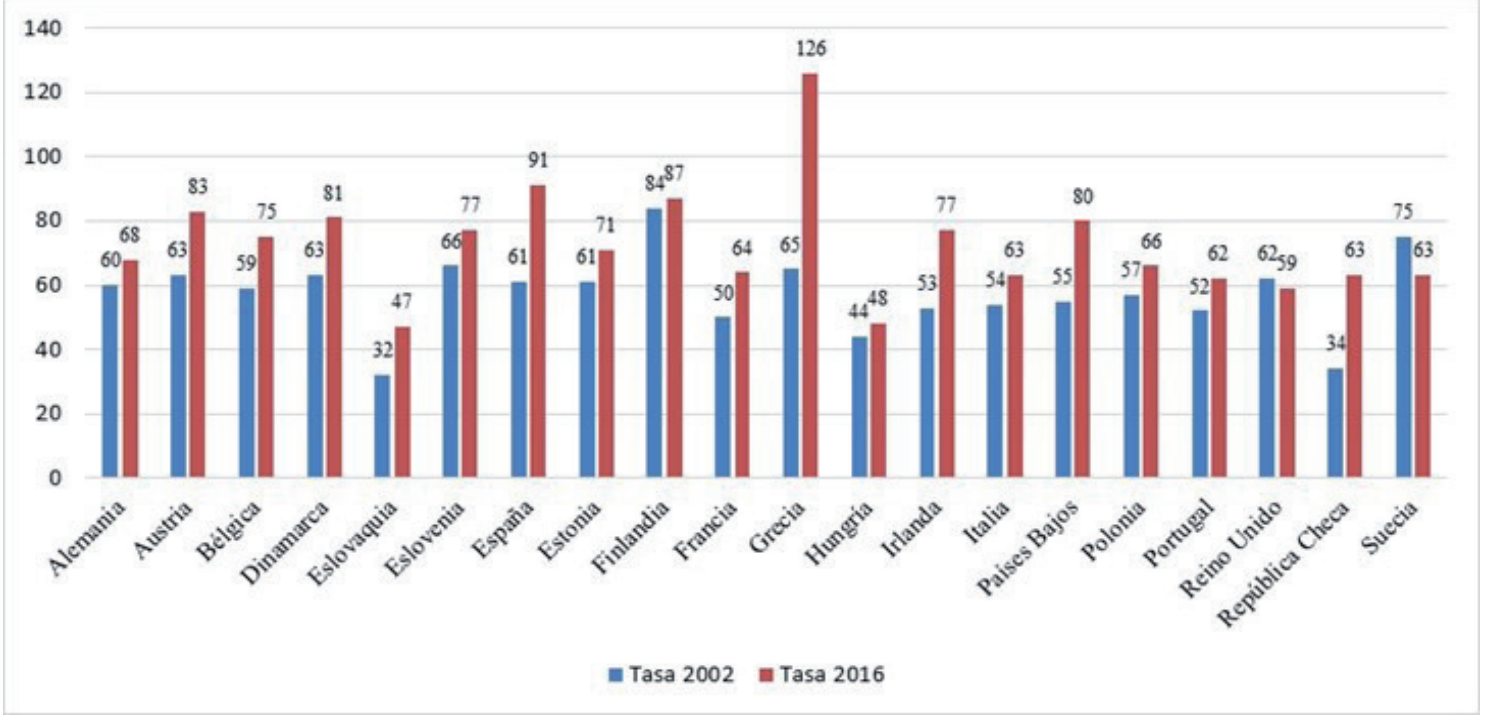

Figura 1. ( \%) Tasa Bruta de Matrícula, en Educación Terciaria, para Ambos Sexos ( \%) 2002 y 2016. Fuente: Elaboración propia. 
En segundo lugar, esta cobertura en la mayor parte de países (17/20) se cubre desde el sector público con porcentajes aproximados o superiores al $80 \%$ de alumnos matriculados en IES públicas para el curso 2017/18. Excepto Reino Unido y Bélgica que sus porcentajes se concentran en IES privadas dependientes del Gobierno. El caso de Finlandia según datos del último curso 2017/18, presenta porcentajes del $67 \%$ de matrícula en IES privadas dependientes del gobierno, pero los estudiantes no pagan tasas de matrícula en estas instituciones. Si bien, podemos destacar una tendencia hacia la privatización de la ES caracterizada por el aumento de alumnos matriculados en IES privadas de 2002 a 2016 en los siguientes países: Austria de $12 \%$ a $18 \%$ en 6 puntos porcentuales (pp de ahora en adelante); Eslovenia de o \% a $7 \%$ (7 pp); Alemania de $2 \%$ a $9 \%$ (7 pp); Francia de $10 \%$ a $17 \%$ (7 pp); Eslovaquia de o \% a $13 \%$ (13 pp); España de $12 \%$ a $18 \%$ (6 pp); e Italia de $7 \%$ a $12 \%(5 \mathrm{pp})$.

\subsection{Comparación de variables}

Basándonos en los datos del indicador «Gasto en instituciones de Educación Terciaria expresado como porcentaje del PIB, por fuente de financiación» de los informes de la OCDE, mostramos el siguiente gráfico, donde comparamos para el año 2002 y el año 2016 las variables de gasto total, gasto público, gasto privado y gasto internacional para los 20 países de la muestra. Esto nos permite valorar cómo han variado los esfuerzos económicos de los diferentes países en instituciones de educación terciaria, en relación a su producto interior bruto, de 2002 a 2016.

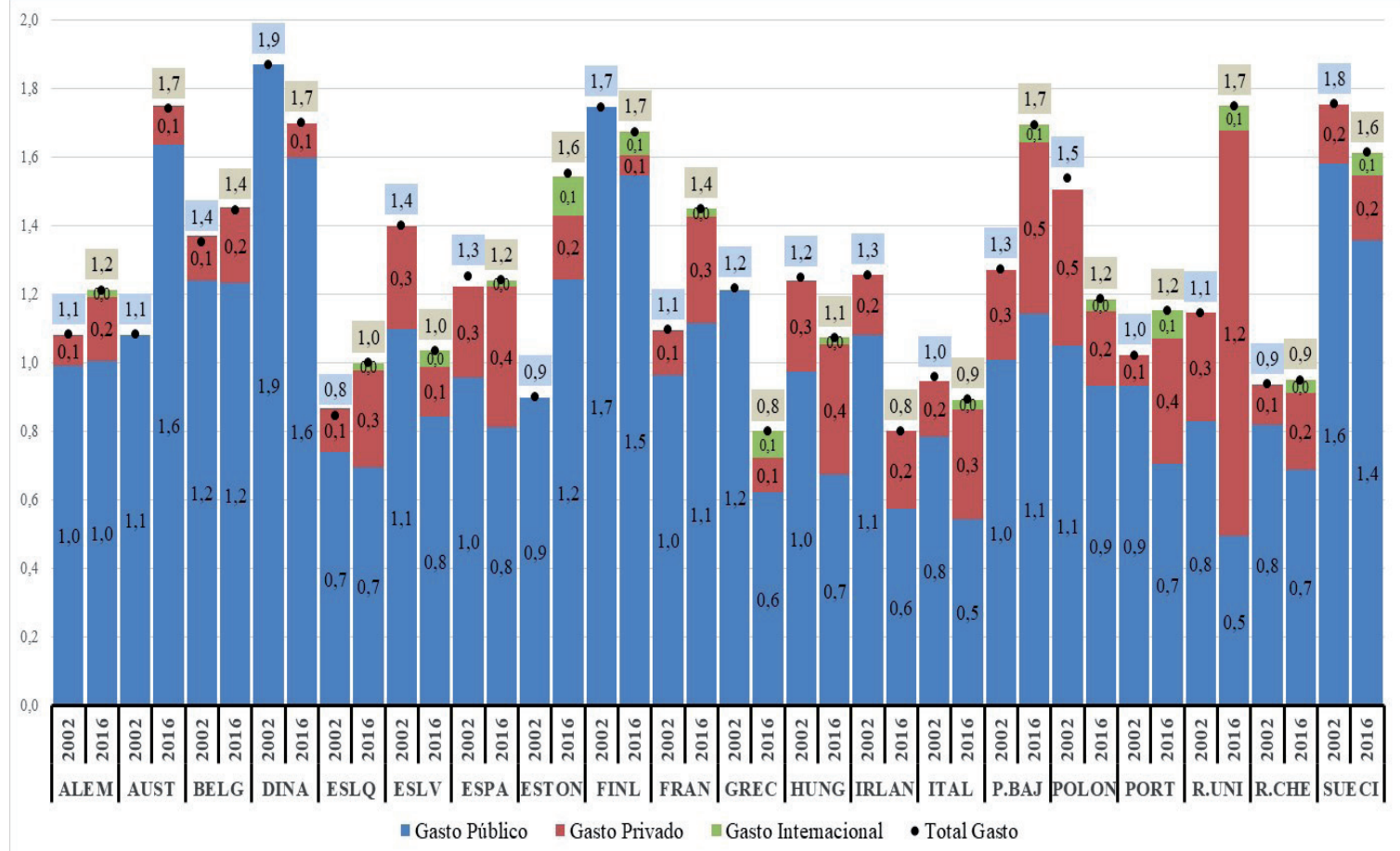

Figura 2. Inversión Total en Instituciones de Educación Terciaria como Porcentaje del PIB, por Fuente de Financiación para 2002-2016. Fuente: Elaboración propia. Notas: Dinamarca datos 2014 (no 2016). Eslovenia datos 2004 (no 2002).

Atendiendo a datos relativos al crecimiento (porcentaje anual) del Producto Interior Bruto (PIB) por país, extraídos de la base de datos de DataBank, de 2002 a 2016, no se aprecian grandes variaciones, pero sí una bajada generalizada entre 2008 y 2009 en 
todos los países. Sin embargo, en 2016 todos los países presentan porcentajes de crecimiento, excepto Grecia con un -0,2\%.

Con los datos proporcionados del indicador «Proporciones relativas del gasto público, privado e internacional en instituciones educativas, como porcentaje, para la educación terciaria» de los informes de la OCDE, presentamos un tercer gráfico, en el cual comparamos para el año 2002 y el año 2016, para los 20 países de la muestra, las variables de gasto público, gasto privado y gasto internacional como porcentaje del gasto total, con el principal objetivo de estudiar en qué medida se han diversificado las fuentes de financiación para instituciones de educación terciaria de 2002 a 2016.

Estos indicadores se basan en la fuente final de fondos, es decir, después de las transferencias de fuentes públicas al sector privado. Por ello, el dinero destinado a becas o prestamos no aparece en el gasto público, sino en el gasto privado, porque se calcula cuando ya ha sido transferido a los estudiantes que forman parte del sector privado. Esto significa que la variable de gasto familiar contempla el importe de tasas económicas que deben pagar los estudiantes y la cuantía económica que reciben como ayuda y que puede cubrir parcial o completamente las tasas, sin diferenciar entre becas y prestamos.

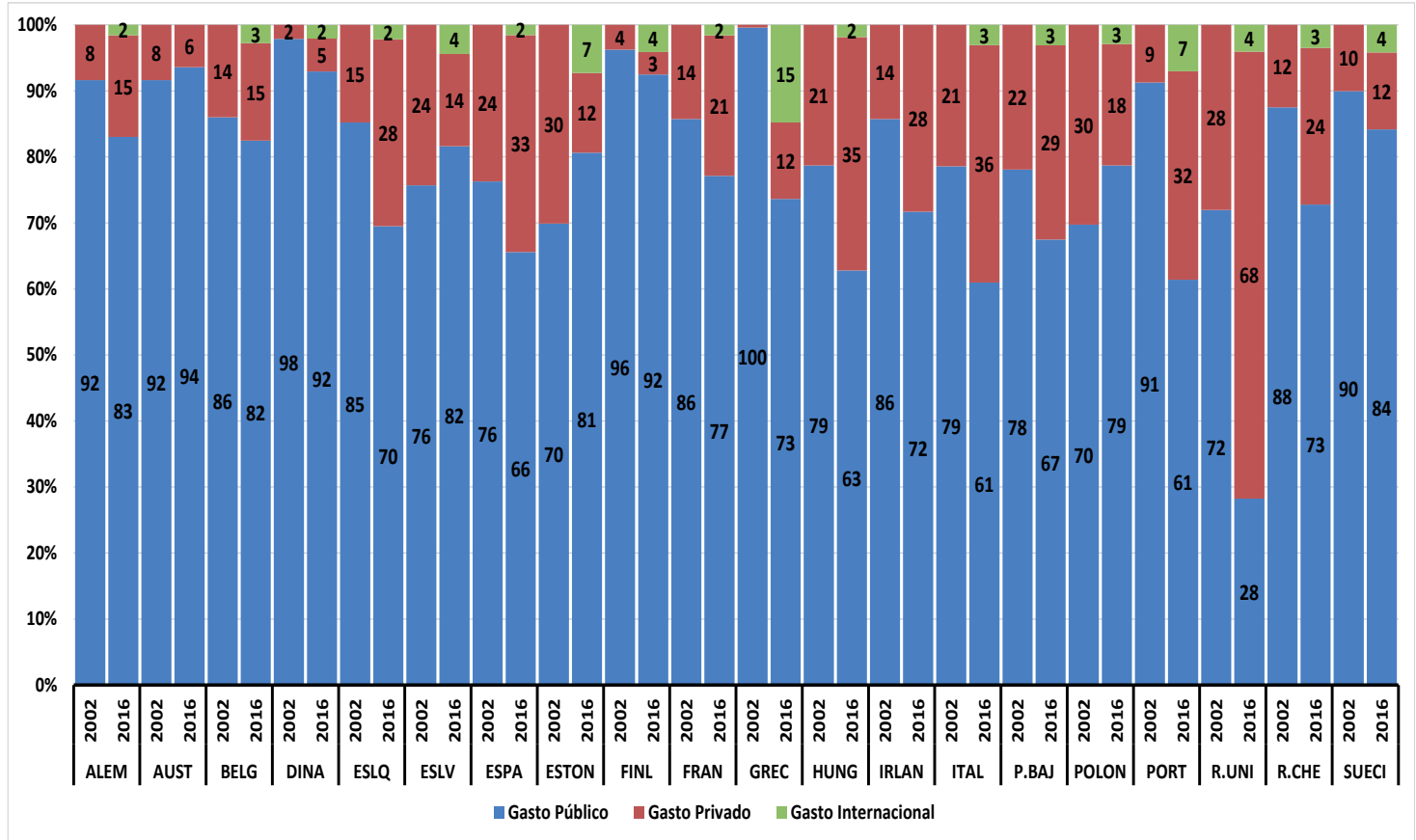

Figura 3. Proporciones Relativas al Gasto de las Instituciones de Educación Terciaria, como Porcentaje del Gasto Total, por Fuente de Financiación para 2002-2016. Fuente: Elaboración propia. Nota: Dinamarca datos 2014 (no 2016), Eslovenia datos 2004 (no 2002), Finlandia y Grecia datos de la base de datos OCDE.Stat para 2016, Grecia para 2015.

Con el propósito de evaluar la variación del modelo de financiación, establecemos una clasificación para que sirva de guía y permita visualizar mejor los cambios. En ella se utilizará el siguiente criterio: por ejemplo, entre 20 y 30, hasta el valor 25, se considerará próximo a 20, y 26 próximo a 30. La clasificación de modelos de financiación de la educación superior, según sus fuentes (públicas y privadas), es la siguiente: 
- Modelos principal o exclusivamente públicos: Entre 80-100 \% de financiación pública y 20-0 \% de financiación privada.

- Modelos mixtos: Entre 50-70 \% de financiación pública y 50-30 \% de financiación privada.

- Modelos privados: Entre 0-40 \% de financiación pública y 60-100 \% de financiación privada.

De acuerdo con la variación de las proporciones relativas al gasto público y privado de 2002 a 2016 como porcentajes del gasto total de la educación terciaria (gráfico 3), se clasifica a los países teniendo en cuenta las categorías anteriores, lo que nos permite estudiar el cambio de modelo de financiación en la trayectoria de tiempo analizada.

Con los datos del segundo indicador, además hemos elaborado un cuarto gráfico, centrado en el análisis del gasto privado para el año 2002 y 2016 para un total de 18 países de la muestra (excepto Alemania y Hungría por falta de datos). En este cuarto gráfico, vemos el porcentaje de inversión privada para cada país en 2002 y 2016, que se exponía en el gráfico 2, pero dividido en las variables: gasto familiar (GF) y gasto de otras entidades privadas (GEP). Esto nos permite analizar la variación del gasto privado, diferenciando entre ambas.

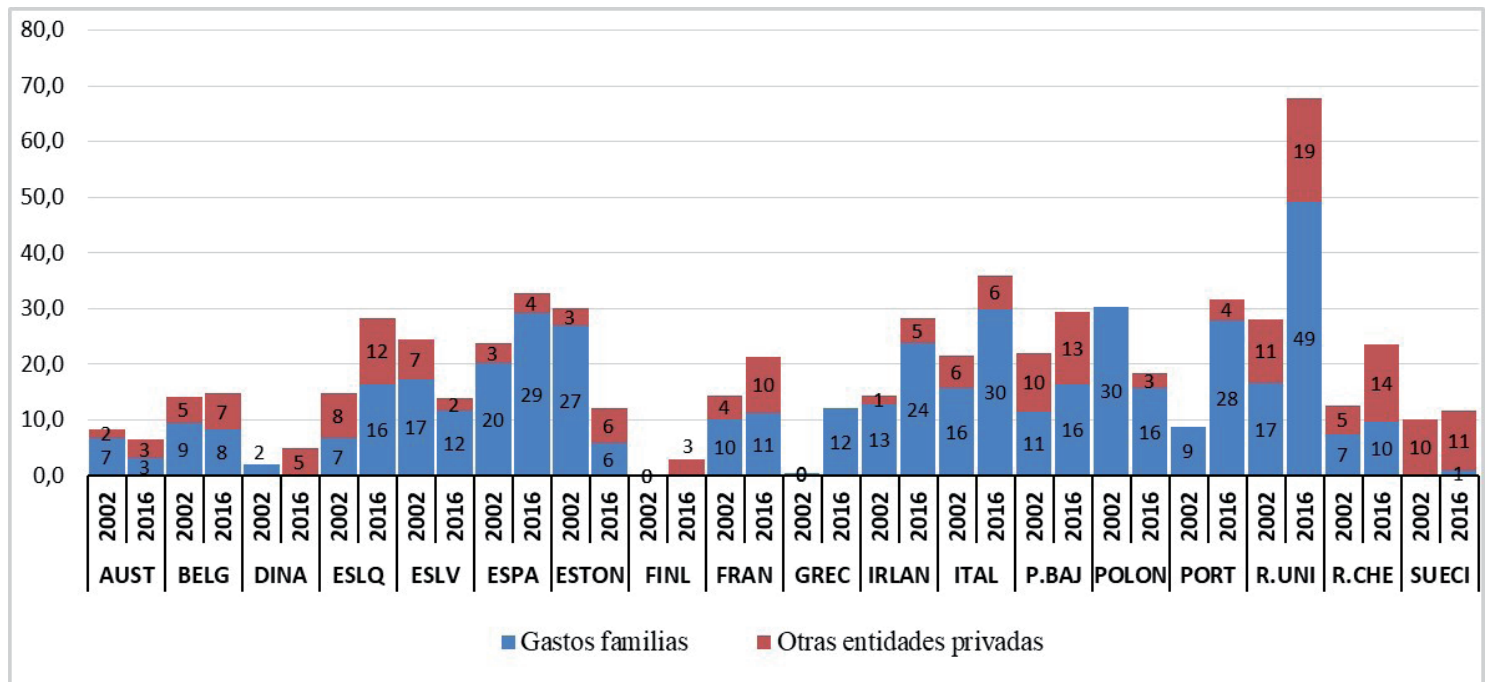

Figura 4. Proporciones Relativas al Gasto Privado como Porcentaje del Gasto Total, Diferenciando entre Gasto Familiar y Gasto de Otras Entidades Privadas (2002-2016). Fuente: Elaboración propia.

\subsection{Modelos de financiación de la educación superior que se mantienen principalmente públicos y garantizan el acceso asequible}

En este bloque encontramos modelos de financiación de la educación superior principalmente o exclusivamente públicos (en torno a 80-100 \% de fuentes públicas, y 20-0 \% de fuentes privadas), que se mantienen en esa categoría en el periodo de tiempo analizado de 2002 a 2016, estos son: Austria, Alemania, Bélgica, Dinamarca, Finlandia y Suecia.

En primer lugar, destacamos el caso de Austria, por ser el único país que presentaba un modelo de financiación público en 2002 y que, en 2016, tenía un modelo de carácter más público. Es el único país que ha seguido esta tendencia de acentuación del modelo 
público, debido al gran aumento de $0,6 \mathrm{pp}$ de inversión pública, que representa el mayor incremento de la muestra de fuentes públicas, y el ligero acrecentamiento en o,1 pp de inversión privada. Su gran inversión pública se ha traducido en que su modelo de financiación pase de $92 \%$ de fuentes públicas a un $94 \%$, y las privadas disminuyan de un 8 $\%$ a un $6 \%$, representando un gasto familiar prácticamente nulo, que incluso ha disminuido de un $7 \%$ a $3 \%$ de 2002 a 2016. Su GF es tan bajo porque, por ejemplo, para el curso 2017/18, los estudiantes nacionales y de la UE estaban exentos del pago de tasas, solo debían abonar tasas de un máximo de $727 €$ anuales los estudiantes internacionales; además, los estudiantes podían beneficiarse de becas (Comisión Europea et al., 2017).

En segundo lugar, destacamos Alemania y Bélgica. Estos países no presentan grandes variaciones, únicamente un leve aumento de 0,1 pp de inversión privada de 2002 a 2016, pero han mantenido sus niveles de inversión pública. Alemania ha pasado de un $92 \%$ de fuentes públicas a un $83 \%$; y en privadas, de un $8 \%$ a un $15 \%$. Bélgica ha variado de 86 $\%$ de públicas a $82 \%$; y las fuentes privadas se han mantenido en un $15 \%$.

Atendiendo a nuestra clasificación, las fuentes de ambos países siguen siendo públicas, a pesar del leve aumento de inversión privada que no ha alterado el GF. En Bélgica, el gasto familiar es muy bajo (apenas un $8 \%$ ). De hecho, los estudiantes pagan tasas de un importe inferior a $1.000 €$, pero además pueden beneficiarse de becas (Comisión Europea et al., 2017), y la mayor parte de alumnos están matriculados en IES privadas dependientes del Gobierno. Respecto a Alemania, no se disponen de datos del porcentaje que corresponde al GF, aunque debe ser mínimo, ya que los estudiantes no pagan tasas económicas y reciben ayudas económicas para el curso 2017/18 (becas, prestamos, beneficios fiscales para los padres y prestaciones familiares) (Comisión Europea et al., 2017). Asimismo, no muestra variaciones del porcentaje de alumnos matriculados en IES privadas.

En tercer lugar, los países nórdicos Dinamarca, Finlandia y Suecia destacaban en 2002 por ser los países con mayor inversión total en IES de educación terciaria y en su totalidad pública. Sin embargo, Suecia presentaba un mínimo de privada en 2002 y, tras disminuir su inversión pública de 2002 a 2016, su modelo ha pronunciado su privatización, pasando de $90 \%$ a $84 \%$ de fuentes públicas, y $10 \%$ a $12 \%$ de fuentes privadas. Finlandia y Dinamarca han pasado de ser completamente públicos en 2002 a presentar valores de inversión privada y disminuir la pública como porcentaje del PIB en 2016, aunque, al igual que Suecia, siguen siendo modelos principalmente públicos.

Los países nórdicos, a pesar de un ligero aumento de inversión privada, no han recaído sobre el gasto familiar y, si nos fijamos en los porcentajes de GF, son inexistentes. Estos países no ponen en riesgo la asequibilidad económica a los estudios superiores, puesto que el acceso es prácticamente gratuito y, además, la gran mayoría de estudiantes se benefician de sistemas de ayudas públicos que costean los gastos de manutención (Comisión Europea et al., 2017), y en el caso de Suecia y Dinamarca, más del 90 \% de estudiantes está matriculado en IES públicas para ambos años (OCDE, 2005, 2019). Finlandia presenta un gran incremento del porcentaje de matrícula en IES privadas dependientes del Gobierno, llegando a representar el $67 \%$ para 2017/18, pero los estudiantes no deben pagar tasas económicas (OCDE, 2019). No obstante, algunas reformas privatizadoras de la ES adoptadas en los tres países nórdicos han sido la introducción de prestamos como sistema de ayudas económicas a estudiantes en combinación con becas o el establecimiento de tasas de matrícula a estudiantes internacionales (OCDE, 2019). 
En resumen, los países de este bloque caracterizados por modelos de financiación principalmente públicos, donde el Gobierno sigue siendo la principal fuente de financiación, no tienden hacia políticas de repartición de costes en ES y, por lo tanto, no se establecen barreras que dificulten el acceso asequible económico de este nivel educativo. Este bloque nos muestra la importancia que tiene el modelo de financiación de la ES público en relación a garantizar un acceso asequible.

No obstante, todos los países han incrementado o incorporado la inversión privada en los últimos años como complemento de la inversión pública, por lo que desarrollan una leve tendencia hacia la privatización de la ES. En el caso de los países nórdicos, que siempre se han caracterizado por un modelo de Estado de Bienestar con una gran inversión pública en educación, en los últimos años han adoptado una serie de medidas pro-privatización que han alterado el carácter público del modelo educativo nórdico, como también señalan otras investigaciones (Verger et al., 2016).

\subsection{Modelos de financiación de la educación superior que tienden hacia una desprivatización y mejoran el acceso asequible de la educación superior}

Países como Polonia, Estonia y Eslovenia han pasado de modelos de financiación de la ES mixtos (en torno 50-70 \% de fuentes públicas y 50-30 \% de fuentes privadas) en 2002 a modelos públicos (en torno a 80-100 \% de fuentes públicas y 20-0 \% de fuentes privadas) en 2016, desarrollando una tendencia hacia la desprivatización, entendida como «el papel decreciente del componente privado en la dinámica cambiante respecto al sector público» (Kwiek, 2016, p. 1).

Estonia y Eslovenia entraron a formar parte de la UE en 2004, es decir, dos años después desde donde parte este estudio. La primera ha incrementado la inversión pública o,3 pp y la privada, en o,2 pp, situándola entre uno de los países que ha experimentado un mayor aumento de su inversión total. El cambio de modelo ha variado de $70 \%$ a $81 \%$ en fuentes públicas y de $30 \%$ a $12 \%$ en privadas.

Eslovenia ha disminuido su inversión pública -0,3 y la privada -0,2 pp, por lo que sus esfuerzos de inversión total han descendido en comparación con 2002. El modelo de financiación ha variado de $76 \%$ a $82 \%$ en fuentes públicas y de $24 \%$ a $14 \%$ en privadas. Polonia también disminuyó la inversión pública y privada; así, el total de inversión en 2016 es más bajo y su modelo ha variado de $70 \%$ a $79 \%$ en públicas, y $30 \%$ a $18 \%$ en privadas.

Son los tres países que más han reducido sus valores porcentuales de inversión privada de 2002 a 2016: Estonia (-18 pp), Polonia (-11 pp) y Eslovenia (-10 pp), incluso podemos decir los únicos, porque solo van seguidos de Austria con valores poco representativos (-2 pp). Esto se ha traducido en que sean los únicos países de la muestra que han bajado su porcentaje de GF, de un modo considerable Estonia (-21 pp) y Polonia (-14 pp), y Eslovenia en valores poco representativos (-5 pp) de 2002 a 2016.

La desprivatización de los modelos en el caso de Polonia y Estonia, ya que Eslovenia no muestra grandes variaciones en su gasto familiar, ha favorecido el acceso asequible de la ES, puesto que el gasto familiar ha disminuido considerablemente.

Polonia ha rebajado el porcentaje de alumnos matriculados en IES privadas de $13 \%$ a $7 \%$, donde pagan tasas académicas mucho más elevadas. Por ejemplo, el promedio anual en 2004/05 era de $2.290 € \mathrm{y}$, para el curso 2017/18, es tanto para grado como para máster 5.308 € en IES privadas (OCDE, 2019), frente a un sector público gratuito.

En Estonia en 2004 los estudiantes pagaban entre 1.849-3.936 € de tasas académicas en IES privadas dependientes del Gobierno, modelo predominante, y desde 2013 
el estudio en estas universidades es gratuito (Eurídice), lo que ha hecho que en comparación con 2016 disminuya considerablemente su GF. Además, ha decaído de 14 \% a $10 \%$ el porcentaje de tasas de matrícula en IES privadas y, para estas instituciones, los alumnos en el curso 2017/18 deben pagar un promedio de tasas académicas de 7.234 $€$ para grado, 7.388 € para máster y o $€$ para doctorado (OCDE, 2019).

En suma, este grupo de países es el único que ha experimentado una desprivatización del modelo de financiación de la ES, mostrando una tendencia opuesta a la generalizada. Para el caso de Polonia y Estonia, como han evidenciado otras investigaciones (Kwiek, 2016) centradas en los países centroeuropeos (Polonia, Estonia, Bulgaria y Rumania), que experimentaron una gran expansión del sector privado en enseñanza superior a partir de la caída de la Unión Soviética (1989), pero en los últimos años se ha producido una decrecimiento demográfico en los casos de Estonia y Polonia (según datos consultados en DataBank). Esto se ha traducido en una disminución de la demanda general de la ES, debilitando al sector privado al presentar cuotas muy elevadas y competir con un sector público donde el acceso es gratuito.

\subsection{Modelos de financiación de la educación superior que tienden hacia la privatización, y casos que desarrollan modelos de repartición de costes que ponen en riesgo el acceso asequible de la educación superior}

En este bloque encontramos el mayor número de los países (Eslovaquia, España, Francia, Grecia, Hungría, Irlanda, Italia, Países Bajos, Portugal y República Checa), lo que nos indica la tendencia predominante del estudio, caracterizada por la privatización de los modelos de financiación de la ES. Se trata de países que han variado de modelos de financiación de la ES públicos (en torno a 80-100 \% de fuentes públicas, y 20-0 \% de fuentes privadas) a modelos mixtos (en torno 50-70 \% de fuentes públicas, y 50-30 \% de fuentes privadas) de 2002 a 2016.

Del total de los diez países que han privatizado claramente su modelo de financiación de ES, si observamos el incremento porcentual de sus fuentes privadas en el gráfico 4, vemos que España, Grecia, Italia, Irlanda, Portugal y Eslovaquia han desarrollado modelos de repartición de costes, aumentando su GF. Estos países son los que pueden poner en riesgo el acceso asequible económico de la ES y, por falta de espacio, solo en ellos centraremos el análisis.

En el resto de países, la privatización de su modelo de financiación lo han ajustado elevando el gasto de otras entidades privadas (República Checa, Francia) o en ambas variables (GF, GEP), de un modo poco significativo en el caso de Países Bajos. El gasto familiar en estos países apenas se ha visto alterado en el periodo analizado y sus valores no son muy elevados, garantizando así el acceso asequible a la educación superior, y las vías de privatización han sido otras diferentes a desviar los costes a los estudiantes. Respecto a Hungría, no se disponen de datos sobre si el aumento de inversión privada recae en gasto familiar $\mathrm{u}$ otras entidades privadas.

La variación del modelo de financiación de 2002 a 2016 ha sido: España de 77 \% a 66 \% de públicas, y $24 \%$ a $33 \%$ en privadas (aumentando 9 pp su GF); Eslovaquia de $85 \%$ a 70 $\%$ para fuentes públicas, y de $15 \%$ a $28 \%$ de fuentes privadas (aumentando 9 pp su GF); Irlanda de $86 \%$ a $72 \%$ públicas y $14 \%$ a $28 \%$ de privadas (aumentando 10 pp su GF); Grecia de un $100 \%$ a un $75 \%$ público y $12 \%$ privado (aumentando 12 pp su GF); Italia de $79 \%$ a $61 \%$ de públicas, y $21 \%$ a $36 \%$ de privadas (aumentando 14 pp su GF); y Portugal de $91 \%$ a 62 \% de fuentes públicas, $9 \%$ a $32 \%$ de privadas (aumentando 20 pp su GF). 
En primer lugar, destacamos los casos de Eslovaquia y Grecia, que han privatizado su modelo de financiación, aumentado su gasto familiar en el periodo analizado. No obstante, en 2016 presentan porcentajes de GF no muy elevados (Eslovaquia 16 \%, Grecia 12 \%), por lo que, a pesar de la tendencia de privatización centrada en desviar costes a los estudiantes, es importante resaltar que el gasto familiar sigue siendo bajo. De hecho, en ambos países la mayoría de estudiantes estuvieron exentos de pagar tasas académicas en 2002 y 2016, incluso en Eslovaquia a nivel de máster y doctorado (OCDE, 2006, 2019; Comisión Europea et al., 2017). El aumento del GF en el caso de Eslovaquia se explica por el incremento de la tasa de matrícula en IES privadas de o \% a $13 \%$ de 2004/05 a 2017/18 (OCDE, 2006, 2019), por lo que este país podemos considerar que no pone en riesgo el acceso asequible, al menos en las IES públicas que dan la mayor cobertura.

En el caso de Grecia tiene recogido en su Constitución proporcionar una educación postsecundaria gratuita (Unesco, 2017) y el $100 \%$ de los estudiantes están matriculados en IES públicas. El aumento de su GF queda representado por el incremento de las tasas académicas a los estudiantes de máster, siendo la media de $3548 €$ para 2017/18 (OCDE, 2019), pero pueden pagar un máximo de $15.000 €$ (Eurídice, 2017), junto con un sistema de ayudas prácticamente inexistente (OCDE, 2019). Este país, por lo tanto, pone en riesgo el acceso asequible económico a la ES a nivel de máster (CINE 7).

En segundo lugar, encontramos a Italia (16 \%), España (20 \%), Irlanda (13\%) y Portugal (9 \%), que ya presentaban porcentajes de GF elevados en 2002 y que en 2016 han aumentado su GF presentando valores bastante altos (Italia $30 \%$, España $29 \%$, Irlanda $24 \%$, y Portugal $28 \%$ ), lo que supone un riesgo para garantizar el acceso asequible económico de la ES.

Como medidas adoptadas, Italia y España han aumentado su promedio anual de tasas económicas para todos los estudiantes (nacionales, de la UE e internacionales) en el periodo analizado. España ha pasado de un promedio anual de tasas de matrícula de $690 €$ en 2004/05 a $1.506 €$ para grado en $2017 / 18$, e Italia de $847 €$ a $1.661 €$ de 2004/o5 a 2017/18 (OCDE ${ }^{1}$, 2006, 2019). Estos países también han elevado el importe de tasas para nivel de máster en 2017/18, una media de $2.478 €$ en España y de $1.853 €$ en Italia (OCDE, 2006, 2019). En lo que respecta a las IES privadas, ambos muestran un aumento del porcentaje de tasa de matrícula de 2002 a 2016, llegando a representar un 18 \% España y un 12 \% Italia en el curso 2017/18, y en este tipo de instituciones los estudiantes pagan importes más elevados (OCDE, 2006, 2019).

Sus sistemas de ayudas públicos se basan en becas, en el caso de España, y prestamos, en el de Italia, pero solo un $1 \%$ se beneficia de este tipo de ayudas para 2017/18 (OCDE, 2019). Ambos han incrementado su porcentaje de gasto público destinado a ayudas económicas: España de un $8 \%$ a un $11 \%$, e Italia de un $15 \%$ a un $25 \%$, de 2002 a 2016 (OCDE, 2006; Eurostat, 2016). En cuanto al número de beneficiarios de ayudas económicas, también se ha elevado de un 34 \% a un 44 \% en España, y mantenido en alrededor de un $38 \%$ en Italia (OCDE, 2006, 2019). Si bien, a pesar de incrementar los esfuerzos económicos destinados a sistemas de ayudas económicas a estudiantes, han sido insuficientes para compensar el aumento del importe de las tasas económicas y número de alumnos matriculados en IES privadas que pagan cuotas más elevadas, lo que ha contribuido a elevar su gasto familiar.

1 Para facilitar la comparación de los datos, hemos convertido el importe de tasas académicas que aparece en los documentos de la OCDE de dólares a euros (con un valor de o,88 EUR). 
En Irlanda, no pagaban tasas académicas en 2004/05 y 2017/18, los estudiantes que accedían por primera vez ni los que eran ciudadanos de la UE, EEE o Suiza (Comisión Europea et al., 2017). El resto de estudiantes pagaba una media de $3.000 €$ en el curso 2017/18 para nivel de grado y, a nivel de máster, la mayoría de estudiantes pagaba tasas que eran fijadas por las IES y que podían ascender hasta $30.000 €$ anuales (Comisión Europea et al., 2017). Los estudiantes internacionales no son elegibles para recibir subvenciones y generalmente están obligados a pagar la tarifa económica que establecen las universidades, que puede variar de 4.000 a 52.000 $€$ (Comisión Europea y Eurídice, 2020). No se dispone de datos sobre la variación del porcentaje de alumnos en IES privadas. El de ayudas públicas lo aumentó de un $12 \%$ a un $38 \%$, de 2002 a 2016 (OCDE 2006, Eurostat 2016). En 2008/o9, el 39 \% se beneficiaba de becas (OCDE, 2011), según el documento Comisión Europea et al. (2017), para el curso 2017/18, el $44 \%$ de los estudiantes de primer ciclo recibieron becas.

Portugal aumentó las tasas económicas, ya que en 2004/o5 pagaban un promedio anual de $748 €$ (OCDE, 2006) y en 2016/17 entre $962 €-1.559 €$, y para este último año, en máster entre $962 €-9.132 €$ (OCDE, 2018). Su importe para estudiantes a tiempo parcial e internacionales, lo establecen las IES. En 2004/5, el 27 \% estaba matriculado en IES privadas y pagaba un promedio de $3.803 €$ (OCDE, 2006), pero no disponemos de datos del porcentaje de matriculados en IES privadas ni precios actuales. El porcentaje de gasto público de ayudas económicas públicas a estudiantes en forma de becas aumentó de un 5 \% a un 12 \% de 2002 a 2016 (OCDE 2006, Eurostat 2016), en cuanto al de beneficiarios, alrededor del $20 \%$ contó con becas tanto para 2004/o5 como para 2017/18 (OCDE, 2006, 2019).

En definitiva, España, Italia, Irlanda, Portugal y Grecia son los países que han privatizado su modelo de financiacion de la ES y esa privatización ha recaído principalmente en un aumento del GF, poniendo en riesgo el acceso asequible de la ES. De esta forma, la privatización del modelo de financiación ha consistido en la desviación de costes a estudiantes: Irlanda mediante el incremento de tasas económicas a estudiantes internacionales y los que no acceden por primera vez a estudios superiores; España e Italia, por el aumento de tasas económicas a nivel de grado y, especialmente, a nivel de máster, junto con un aumento de matrícula en IES privadas; Portugal por el aumento de tasas en grado y máster a estudiantes internacionales; y Grecia aumentado las tasas a nivel de máster. Todo ello con sistemas de ayudas económicas pobres, ya que, a pesar de que los cuatros países han aumentado sus esfuerzos económicos en una mayor inversión en los sistemas de ayudas, menos de la mitad de estudiantes se beneficia de becas.

El llamado grupo PIIGS, conformado por Portugal, Italia, Irlanda, Grecia y España representan el conjunto de países que fueron fuertemente golpeados por la crisis económica 2008-09, presentando graves problemas de déficit público. Esto ha conllevado a que abordaran forzosamente medidas de austeridad para reducir el déficit y la deuda nacional (Duque Romero, 2015), y en el ámbito de la ES, se ha producido una clara disminución de inversión pública y un aumento de inversión privada, trasladando los costes a los estudiantes.

\subsection{Modelo de financiación de la educación superior privado, que asegura la asequibilidad de la educación superior}

En este último bloque, solo encontramos el caso de Reino Unido (Inglaterra, Escocia, Gales e Irlanda del Norte), pasando de un modelo de financiación de la ES mixto (entre 
50-70 \% en financiación pública y 50-30 \% en financiación privada) en 2002, a un modelo de financiación privado (40 \% de financiación pública y 60-100 \% de financiación privada) en 2016. El modelo de financiación ha pasado de $72 \%$ de públicas a $28 \%$, y en privadas de $28 \%$ a $68 \%$, aumentando tanto el GEP como el GF.

Esta región disminuyó en -0,3 pp la inversión pública y aumentó más que ningún país, en $0,9 \mathrm{pp}$, la privada. Ese gran incremento le ha llevado a ser uno de los países de mayor inversión total como porcentaje del PIB en instituciones de educación terciaria en 2016.

Reino Unido ha sido la región que más ha aumentado su GF de toda la muestra en 32 pp, de $17 \%$ a $49 \%$ de 2002 a 2016. Sin embargo, ha establecido una política de distribución de costes en ES a través de altas tasas de matrícula y fuertes sistemas de ayudas a estudiantes, basados en prestamos universitarios que garantiza el acceso asequible de la ES.

Reino Unido presenta importes de tasas académicas muy elevados para IES privadas dependientes del Gobierno (único tipo de institución que existe). De hecho, es el que más ha aumentado sus tasas académicas de la muestra, pasando de un promedio anual de $1.547 €$ en 2004/o5 (OCDE, 2006) a 10.235 € en 2017/18 (OCDE, 2019) para estudiantes nacionales a nivel de grado. Los estudiantes internacionales, que representan alrededor del 20 \% para el curso 2017/18 (OCDE, 2019), deben pagar importes más elevados y las IES tienen autonomía para decidir el importe (Comisión Europea et al., 2017).

$\mathrm{Al}$ mismo tiempo, ha establecido un sistema de ayudas basado en prestamos, cuyo porcentaje del gasto público total en educación ha variado de un $23 \%$ a un $63 \%$ de 2002 a 2016, por lo que ha incrementado notablemente el dinero público destinado a ayudas económicas (OCDE 2005, Eurostat 2016). Su sistema de prestamos cubre el importe total de matrícula y los costes de manutención (Comisión Europea et al., 2017), y alrededor del 94 \% de estudiantes se beneficia de un prestamo (OCDE, 2019). Estos datos indican que su GF debería ser nulo, pero aparece tan alto porque Reino Unido fiscaliza el importe de los prestamos de un modo que no aparece reflejado en la variable de GF, según los expertos a los que hemos consultado, como Tristán McCowan.

Consecuentemente, dicha región garantiza el acceso asequible, pero con prestamos que luego los estudiantes deben amortizar con importes muy elevados. De hecho, la media anual para 2017 de la cuantía económica que recibe un alumno mediante el prestamo es de $14.728 €$, llegando a generar deudas al final de la educación terciaria de una media de $43.071 €$ y tardan una media de 30 años en amortizarlo (OCDE, 2019). No obstante, un 70 \% queda exento del pago de los prestamos (OCDE, 2019), primordialmente porque la devolución del prestamo está condicionada a los ingresos futuros de los estudiantes (OCDE, 2019).

La privatización de la ES en Reino Unido, la situamos tras el gobierno de Margaret Thatcher (1970-1990) con la aplicación de políticas neoliberales, agravándose en 2010, con el gobierno conservador de David Cameron que de forma voluntaria tras la crisis económica, aplicó políticas de austeridad económica para reducir la deuda pública (Duque Romero, 2015).

\section{Conclusiones}

En general, es evidente que uno de los principales objetivos que se promueven desde la reforma europea es de carácter económico, ya que su principal pretensión es ser la región más competitiva del planeta. En esta línea, la UE resalta el gasto público como la principal base económica de los sistemas educativos, pero justifica que resulta insuficiente 
ser asumido solo por el Estado el gasto total que se requiere en una economía basada en el conocimiento, alentando a los Estados miembros a que incrementen la financiación privada, especialmente mediante el traslado de los costes a los estudiantes.

Tras analizar las tendencias de los modelos de financiación de los 20 países europeos de 2002 a 2016, podemos destacar que solo la mitad (10/20) ha conseguido aumentar su inversión total; y que existe una tendencia hacia la disminución de inversión pública (13/20) y mayoritariamente hacia el aumento de la inversión privada (17/20). Estos datos a rasgos generales muestran que queda lejos el objetivo propuesto por la UE de alcanzar al menos un $2 \%$ del PIB en educación terciaria, puesto que los países que más se aproximan tiene valores de $1,7 \%$ del PIB. Asimismo, las dos tendencias dominantes están generando graves consecuencias en dos agrupaciones de países.

Entre esas tendencias está Reino Unido, el único modelo privado, que a pesar de mostrar gran reducción del gasto público en ES ha conseguido niveles de inversión total en ES de los más altos de todos países de la muestra y que, además, es considerado un modelo competitivo en el mercado educativo internacional (Brunner et al., 2019). Este caso representa la privatización de la ES como consecuencia de una reforma estructural del modelo de Estado, optando por uno minimalista basado en la ideología neoliberal, como señalaron Verger et al., (2016).

Reino Unido ha desarrollado un modelo donde todos los recursos económicos públicos se desvían a los estudiantes en forma de ayudas económicas, básicamente en prestamos, en vez de a las IES, y son estas las que compiten por atraer a los estudiantes, y reciben el dinero a través del pago de las tasas de matrículas. El elevado importe de las tasas de matrícula queda completamente cubierto por los prestamos y prácticamente todos los estudiantes se benefician de esta ayuda, y de este modo, se asegura la asequibilidad de la ES. Es un modelo que aunque garantice el acceso asequible, obliga a los estudiantes a adoptar una actitud inversora, generándoles enormes deudas que pueden tardar hasta tres décadas en ser saldadas.

Por otra parte están países los PIIGS (Portugal, Italia, Irlanda, Grecia y España) sufrieron grandes desequilibrios económicos tras la crisis económica, y se vieron forzados que desarrollar políticas de austeridad económica que requerían del recorte del gasto público, asociadas en muchos casos a la ideología neoliberal (Duque Romero, 2015). Todos ellos presentan escenarios de reducción del gasto público en ES y un desvío de los costes a los estudiantes. Esto ha repercutido en el acceso asequible de la ES porque no se ha contado con buenos sistemas de ayudas económicas. Los citados contextos requieren de una mayor profundización para comprender sus procesos de privatización, sobre todo de la influencia de la UE a través de las medidas de ajuste estructural y contención del gasto público, y con más sentido, en el escenario que nos encontramos actualmente por la COVID-19, que traerá un agravamiento de la situación económica.

En suma, si la influencia que ejercen organismos supranacionales como la UE sobre la configuración de políticas educativas termina alienando políticas centradas en el aumento de la inversión en ES para ser competitivos en la sociedad del conocimiento, y la tendencia de la mayoría de países es incrementar la participación del sector privado, las cuestiones principales se convierten en: cómo seguir garantizando unos niveles de inversión pública adecuados, ya que son la mejor garantía para el acceso asequible de la ES, sobre todo en contextos de austeridad económica; y cómo evitar modelos que, bajo la concepción de la ES como un bien de inversión individual, generen mayor desigualdad o enormes deudas entre los estudiantes. 


\section{Referencias}

Brunner, J. J., Vargas, J. R. L., Ganga, F., y Rodríguez-Ponce, E. (2019). Teoría del capitalismo académico en los estudios de educación superior. Revista Electrónica de Investigación Educativa, 21(1), 1-13. https://redie.uabc.mx/redie/article/ view/3181

Caballero, A., Manso, J., Matarranz, M., y Valle J. M. (2016). Investigación en Educación Comparada: Pistas para investigadores noveles. Revista latinoamericana de Educación comparada, 7(9), 39-56. http://www.saece.com.ar/relec/revistas/9/ art3.pdf

Comisión Europea (2002). Educación y Formación en Europa: sistemas diversos, objetivos compartidos para 2010. Programa de trabajo sobre los futuros objetivos de los sistemas de educación y formación. http://www.educaragon.org/files/ educacion_y_formacion_2010.pdf

Comisión Europea/EACEA/Eurydice, 2017. Sistemas nacionales de tasas y ayudas a los estudiantes en la educación superior europea - 2017/18. Datos y cifras de Eurydice. Luxemburgo: Oficina de Publicaciones de la Unión Europea. https://op.europa. eu/en/publication-detail/-/publication/c052429f-b92e-11e7-a7f8-01aa75ed71a1/ language-es

Comunicación de la Comisión al Consejo y al Parlamento Europeo, del 10 de mayo de 2006. Cumplir la agenda de modernización para las universidades: educación, investigación e innovación. COM (2006) 208. https://eur-lex.europa.eu/ LexUriServ/LexUriServ.do?uri=COM:2006:0208:FIN:ES:PDF

Comunicación de la Comisión al Consejo y al Parlamento Europeo, el 8 de septiembre de 2006. Eficiencia y equidad en los sistemas europeos de educación y formación. COM (2006) 481. https://eur-lex.europa.eu/LexUriServ/LexUriServ. do?uri=COM:2006:0481:FIN:ES:PDF

Comunicación de la Comisión al Parlamento Europeo, al Consejo, al Comité Económico y Social Europeo y al Comité de las regiones, el 20 de septiembre de 2011. Apoyar el crecimiento y el empleo: una agenda para la modernización de los sistemas de educación superior en Europa. COM (2011) 567. https://eur-lex.europa.eu/legalcontent/ES/TXT/PDF/?uri=CELEX:52011DC0567\&from=FR

Comunicación de la Comisión al Parlamento Europeo, al Consejo, al Comité Económico y Social Europeo y al Comité de las Regiones, el 30 de mayo de 2017. Sobre una agenda renovada de la UE para la educación superior. COM (2017) 247. https://eur-lex. europa.eu/legal-content/ES/TXT/PDF/?uri=CELEX:52017DCo247\&from=EN

Comunicación de la Comisión, de 10 de enero de 2003. Invertir eficazmente en educación y formación: un imperativo para Europa. COM (2002) 779. https://eur-lex.europa. eu/legal-content/ES/TXT/PDF/?uri=CELEX:52002DCo779\&from=ES 
Comunicación de la Comisión, de 5 de febrero de 2003. El papel de las universidades en la Europa del conocimiento. COM (2003) 58. https://eur-lex.europa.eu/LexUriServ/ LexUriServ.do?uri=COM:2003:0058:FIN:ES:PDF

Comunicación de la Comisión, de 20 de abril de 2005. Movilizar el capital intelectual de Europa: crear las condiciones necesarias para que las universidades puedan contribuir plenamente a la Estrategia Lisboa. COM (2005) 152. https://eur-lex. europa.eu/LexUriServ/LexUriServ.do?uri=COM:2005:0152:FIN:ES:PDF

Comunicación de la Comisión, el 3 de marzo de 2010. Europa 2020, una estrategia para un crecimiento inteligente, sostenible e integrador. COM (2010) 2020. https://eur-lex. europa.eu/legal-content/ES/TXT/PDF/?uri=CELEX:52010DC2020\&from=ES

Conclusiones de la Presidencia del Consejo Europeo de Lisboa, de 23 y 24 de marzo de 2000. http://www.europarl.europa.eu/summits/lis1_es.htm

Dale, R. (2007). Los efectos de la globalización en la política nacional: un análisis de los mecanismos. En X. Bonal, A. Tarabini-Castellani, y A. Verger (Comps.), Globalización y educación. Textos fundamentales, (pp. 87-114). Argentina: Miño y Dávila.

Diario Oficial de la Unión Europea, C 119/2, 28 de mayo de 2009. Conclusiones del Consejo de 12 de mayo de 2009 sobre un marco estratégico para la cooperación europea en el ámbito de la educación y la formación (ET 2020). (2009/C 119/02). https://eur-lex.europa.eu/legal-content/ES/TXT/ $\mathrm{PDF} /$ ?uri=CELEX:52009XGo528(01)\&from $=\mathrm{ES}$

Duque Romero, J.J (2015). La austeridad económica en el sur de Europa durante la Gran Recesión. Factótum: Revista de filosofía, (14), 1-21. http://www.revistafactotum. com/revista/f_14/articulos/Factotum_14_1_Juan_Jesus_Duque.pdf

Kwiek, M. (2017). La desprivatización en la educación superior: un enfoque conceptual. Revista de la educación superior, 46(182), 1-26. https://www. sciencedirect.com/science/article/pii/So185276017300298

Luzón, A., y Torres, M. (2013). Apuntes sobre la internacionalización y la globalización en educación: de la internacionalización de los modelos educativos a un nuevo modelo de gobernanza. Journal of supranational policies of education, 1, 53-66. https://repositorio.uam.es/handle/10486/667154

Maria Chiodi, F. (2015). La coordinación de las políticas de protección social en Europa. En Coordinación de políticas sociales: desafíos para la gestión pública, pp. 135-174. Programa EUROSocial, http://www.repositorio.fjp.mg.gov.br/jspui/ bitstream/123456789/2203/1/Libro_Coordinaci\%C3\%B3n_pol\%C3\%ADticas_ sociales.pdf\#page $=137$

Matarranz García, M. (2017). Análisis supranacional de la política educativa de la Unión Europea (200O-2015). Hacia un espacio europeo de educación [Tesis doctoral, Universidad Autónoma de Madrid]. https://repositorio.uam.es/ handle/10486/682755 
Matarranz, M., y Pérez, T. (2016). ¿Política Educativa Supranacional o Educación Supranacional? El debate sobre el objeto de estudio de un área emergente de conocimiento. Revista Española de Educación Comparada, 28, 91-107. http:// e-spacio.uned.es/fez/eserv/bibliuned:reec-2016-numero28-5020/Politica_ educativa_supranacional.pdf

OCDE (2002). Education at a Glance 2002: OECD Indicators, OECD Publishing, Paris. https://www.oecd-ilibrary.org/education/education-at-a-glance-2002_eag2002-en

OCDE (2005). Education at a Glance 2005: OECD Indicators, OECD Publishing, Paris. https://www.oecd-ilibrary.org/education/education-at-a-glance-2003_eag2003-en

OCDE (2006). Education at a Glance 2006: OECD Indicators, OECD Publishing, Paris. https://www.oecd-ilibrary.org/education/education-at-a-glance-2006_eag2006-en

OCDE (2008). Education at a Glance 2008: OECD Indicators, OECD Publishing, Paris. https://www.oecd-ilibrary.org/education/education-at-a-glance-2008_eag2008-en

OCDE (2011). Education at a Glance 2011: OECD Indicators, OECD Publishing, Paris. https://www.oecd-ilibrary.org/education/education-at-a-glance-2011_eag-2011en

OCDE (2016). Education at a Glance 2016: OECD Indicators, OECD Publishing, Paris. https://www.oecd-ilibrary.org/education/education-at-a-glance-2016_eag-2016en

OCDE (2018). Education at a Glance 2018: OECD Indicators, OECD Publishing, Paris. https://www.oecd-ilibrary.org/education/education-at-a-glance-2018_eag-2018en

OCDE (2019). Education at a Glance 2019: OECD Indicators, OECD Publishing, Paris. https://www.oecd-ilibrary.org/education/education-at-a-glance-2019_ f8d788od-en

Rizvi, F.(2016). La privatización en la educación: tendencias y consecuencias. Documentos de trabajo de IPE, 18. https://unesdoc.unesco.org/ark:/48223/pfoooo246485_ spa

Tarabini-Castellani, A., y Bonal, X. (2011). Globalización y política educativa: los mecanismos como método de estudio. Revista de educación, 355, 235-255. DOI: 10-4438/1988-592X-RE-2011-355-023

Tilak, J. B. (2006). La educación superior privada: de la filantropía a los beneficios. En La educación superior en el mundo 2006: La financiación de las universidades (pp. 112-120). España, Madrid: Ediciones Mundi-Prensa. https://upcommons. upc.edu/bitstream/handle/2099/6958/2006-02_esp_tilak.pdf 
Unesco (2017). Informe de seguimiento de educación en el mundo 2017/8. Rendir cuentas en el ámbito de la educación: cumplir nuestros compromisos. https:// unesdoc.unesco.org/ark:/48223/pfoooo261016

Valle, J. M. (2012). La política educativa supranacional: un nuevo campo de conocimiento para abordar las políticas educativas en un mundo globalizado. Revista Española de Educación Comparada, 20, 109-144. https://repositorio.uam.es/ handle/10486/660724

Valle, J. M. (2015). Las políticas educativas en tiempos de globalización: la educación supranacional. Bordón. Revista de Pedagogía, 67(1), 11-21. DOI: 10.13042/ Bordon.2015.67101

Verger, A. (2013). Políticas de mercado, Estado y universidad: hacia una conceptualización y explicación del fenómeno de la mercantilización de la Educación Superior. Revista de educación, 360, 268-291. Recuperado de: https://core.ac.uk/download/ pdf/78545928.pdf

Verger, A., Zancajo, A., y Fontdevila, C. (2016). La economía política de la privatización educativa: políticas, tendencias y trayectorias desde una perspectiva comparada. Revista colombiana de educación, (70), 47-78. http://www.scielo.org. co/pdf/rcde/n7o/n70ao4.pdf 